\title{
Validation of Waste Anaesthetic Gas Exposure Limits When Using a Closed Vaporizer Filling System: A Laboratory-Based Study
}

\author{
Shane Varughese $\cdot$ H. Peter Bacher
}

Received: September 26, 2019 / Published online: December 4, 2019

(C) The Author(s) 2019

\section{ABSTRACT}

Introduction: It is desirable to minimise exposure of personnel to halogenated inhaled anaesthetics in the operating room to avoid deleterious short-term and long-term health effects. The objective of this study was to determine whether, while filling anaesthetic vaporizers with sevoflurane using AbbVie's closed vaporizer filling system (Quik-Fil ${ }^{\mathrm{TM}}$ ), concentrations of sevoflurane in ambient air remained at or below recommended levels when measured at different operator heights.

Methods: Nine filling runs were conducted, with measurement heights of $95,130,140,150$, 160 , and $185 \mathrm{~cm}$. Within each 15-min run, five vaporizers were sequentially filled from bottles of sevoflurane with the closed valving system. Ambient-air sevoflurane concentration in the breathing zone was continuously measured

Enhanced Digital Features To view enhanced digital features for this article go to https://doi.org/10.6084/ m9.figshare.10303706.

S. Varughese $(\bowtie) \cdot$ H. P. Bacher

Global Medical Affairs, AbbVie Inc, North Chicago,

IL, USA

e-mail: shane.varughese@abbvie.com once per second by using a MIRAN SapphIRe 205BXL portable ambient air analyser.

Results: The use of the closed filling system maintained a level of waste anaesthetic gas exposure that was well below (mean, $0.10 \mathrm{ppm}$; maximum, $0.16 \mathrm{ppm}$ ) the recommended shortterm value of $20 \mathrm{ppm}$ average for $15 \mathrm{~min}$ provided by the Swedish Work Environment Authority and also fell below the US limit of a time-weighted average of $2 \mathrm{ppm}$ provided by the National Institute for Occupational Safety and Health. Exposure to sevoflurane appeared to be independent of the height at which the measurement was made.

Conclusions: The presence of sevoflurane in the work environment while using the closed filling system maintains a level of waste anaesthetic gas exposure well below the recommended levels at all tested operator heights.

Keywords: Awareness; Equipment issues; Factors affecting vaporizer output; Inhaled anaesthetic; Sevoflurane 
Key Summary Points

Why carry out this study?

Exposure to waste anaesthetic gases (WAGS) that leak into operating rooms during anaesthetic delivery can lead to short-term and long-term adverse effects.

Although precautionary practices are often implemented to minimise anaesthetic gas leakage, leakage can still occur (e.g. during filling of vaporizers).

The aim of this study was to test the hypothesis that use of a closed valve vaporizer filling system would maintain the presence of sevoflurane within or below recommended exposure limits.

\section{What was learned from this study?}

Sevoflurane exposures in the breathing zone were well below the recommended guidance from both National Institute for Occupational Safety and Health (NIOSH) and the Swedish Work Environment Authority for exposure limits when the vaporizer is filled using a closed filling system.

Use of the closed vaporizer filling system evaluated here can help to minimise occupational exposure to WAGs in an operating room environment.

\section{INTRODUCTION}

The US National Institute for Occupational Safety and Health (NIOSH) defines waste anaesthetic gases (WAGs) as small amounts of volatile anaesthetic gases leaking into operating rooms during anaesthetic delivery $[1,2]$. In the USA, chronic exposure to WAGs affects more than 200,000 healthcare professionals, including anaesthesiologists, surgeons, operating room nurses and technicians [1, 3, 4]. Shortterm exposure (acute; during or within hours after anaesthesia procedure) to high concentrations of WAGs could lead to headache, irritability, nausea and drowsiness immediately upon or shortly after exposure, whereas longterm exposure (chronic; working over months or years in an operating room setting) to low concentrations is associated with genetic anomalies, miscarriage, birth defects and malignancy that may occur after several months [1, 5-8].

Waste gases include nitrous oxide and halogenated anaesthetics [1]. Halogenated compounds are among the most common anaesthetics in clinical practice [9]. Halogenated inhaled anaesthetics are volatile liquids that are transferred from a closed bottle to a vaporizer using a valving system, which allows the anaesthetic agent to be poured into the vaporizer [10]. Although precautionary practices are often set to minimise excess anaesthetic gas leakage [2, 5], contamination of operating rooms can still occur through different pathways, including improper anaesthetic handling techniques that cause spillage of anaesthetics during the filling of vaporizers [11].

The effects of anaesthetic gas exposure are dependent on the concentration of the agent and the duration of exposure. Sevoflurane is one of the most widely used inhaled anaesthetic agents $[9,12,13]$. Although no US federal regulatory standard exists for sevoflurane exposure limits [9], NIOSH guidelines advise that occupational exposure limits to halogenated gases should not exceed a 60 -min ceiling of $2 \mathrm{ppm}$ over the period of anaesthetic administration $[2,12]$. The US National Institutes of Health also recommends an occupational exposure limit of sevoflurane to $2 \mathrm{ppm}$ as a time-weighted average (TWA) representing the average exposure over a schedule of $8 \mathrm{~h}$ per day or $40 \mathrm{~h}$ per week [14]. In Europe, the Swedish Work Environment Authority recommends a short-term value of 20 ppm average over 15 min [15].

Use of a closed valving system to fill anaesthetic vaporizers with sevoflurane has been shown by Heijbel et al. to result in $63 \%$ lower levels of waste gas exposure compared with concentrations observed during use of a different filling system $(P=0.016)$ [16]. However, the study by Heijbel et al. did not measure 
sevoflurane concentrations at different heights. Ready-to-use sevoflurane bottles incorporating AbbVie's closed valving system (Quik-Fil ${ }^{\mathrm{TM}}$; AbbVie Inc., North Chicago, IL, USA) are now available. The objective of this study was to establish the validation of the previous study by Heijbel et al. [16] to further demonstrate that, while using this closed valving system, the presence of sevoflurane in the breathing zone as normally located in an operating room would be within or below recommended exposure limits at different heights.

\section{METHODS}

This was a prospective, open, exploratory study conducted in a laboratory setting at room temperature (approximately $20-21^{\circ} \mathrm{C}$ ). The laboratory where the experiment was conducted had an air handling system that displaced approximately 6-12 volume changes per hour, to approximate the air exchange rate of an operating room. The study was sponsored by AbbVie Inc. (North Chicago, IL, USA), and the working procedure was reviewed and approved by AbbVie Global Medical Affairs.

\section{Filling Technique}

The experimental setup and filling procedure are depicted in Fig. 1. Nine separate filling runs were performed in this study. In each run, five Dräger Vapor ${ }^{\circledR} 2000$ vaporizers (Dräger Medical AG \& Co. KGaA, Lübeck, Germany) were sequentially filled with sevoflurane (Ultane ${ }^{\circledR}$, AbbVie Inc., North Chicago, IL, USA) from anaesthetic bottles kept at room temperature and using the integrated closed valving system. Within each run, the first vaporizer was filled, which took approximately $3 \mathrm{~min}$, then that vaporizer was closed and filling of the next vaporizer began; this continued until the fifth vaporizer was full, so that the total time of each run was approximately $15 \mathrm{~min}$. Each vaporizer was filled from a new bottle. The number of vaporizers per run and the total time per run were based on usual practice for this type of study. The five vaporizers for each run were taken from a pool of 25 calibrated vaporizers; because a total of 45 vaporizer fillings (nine runs $\times$ five fillings per run) were completed in the study, some vaporizers were reused, after complete drying.

The filling procedure was performed by two operators, who were laboratory personnel; operator A was $168 \mathrm{~cm}$ tall and had very little experience filling anaesthetic vaporizers, and operator B was $186 \mathrm{~cm}$ tall and had 10 years of experience filling anaesthetic vaporizers.

\section{Measurement of Sevoflurane Concentrations}

The maximum and minimum ambient-air sevoflurane concentrations in the breathing zone (midway between the vaporizer and approximately $15 \mathrm{~cm}$ from the nose or mouth) during the 15-min fill time were measured in units of ppm every second (total of approximately 900 measurements per vaporizer per 15-min run period) using a MIRAN SapphIRe 205BXL (Thermo Fisher Scientific, Franklin, MA, USA). This device is part of a family of air analysers that utilise infrared detection to monitor the presence of gases in ambient air. By selecting a measurement wavelength for the target gas that is not common to any other gas, the problem of interference by other components of the air can be avoided. A microcontroller automatically handles the analysis, processes the measurement signal, and calculates the absorbance values.

To assess sevoflurane exposure at different typical operator positions (i.e. sitting and standing, with the breathing zone close to and far from the vaporizer, respectively), ambient sevoflurane air concentrations were measured with the air analyser at different heights relative to the floor in each of the nine runs: 95,130 , $140,150,160$, and $185 \mathrm{~cm}$. The vaporizers remained at a fixed height from the floor $(125 \mathrm{~cm}$ to the fill valve and $130 \mathrm{~cm}$ to the mounting point). Observed sevoflurane concentrations were compared against the recommended short-term value of $20 \mathrm{ppm}$ average for 15 min provided by the Swedish Work Environment Authority and the US limit of a TWA 

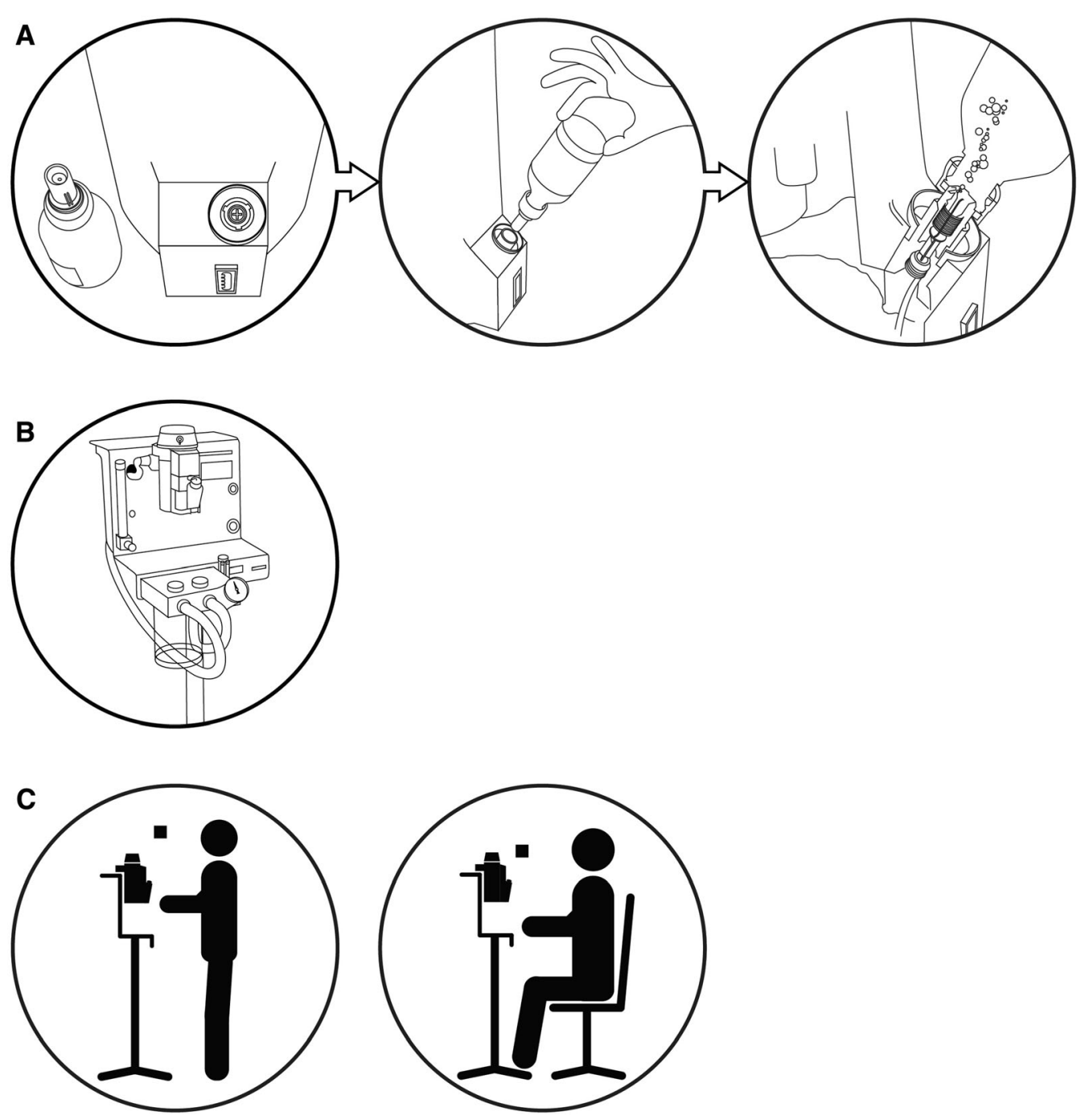

Fig. 1 Filling procedure and experimental setup. a To fill the individual vaporizers using the closed valving system, operators inserted a bottle of sevoflurane directly into the vaporizer; filling was accomplished by gravity-based flow. b The equipment setup included a vaporizer mounted to a fixed-height interface and an ambient air analyser placed at

of $2 \mathrm{ppm}$ during $1 \mathrm{~h}$ or less provided by the NIOSH $[2,15]$.

\section{Compliance with Ethics Guidelines}

This work represents a laboratory study; no ethical committee approval was required and no human subjects were involved.

different heights. Five vaporizers were filled per run, and nine total runs were performed; the height of the air analyser varied across runs. c Vaporizer filling was performed in a standing or sitting position to accommodate operator height, with the air analyser (black square) placed at various heights in the breathing zone

\section{RESULTS}

Under the circumstances of this study, the use of the closed vaporizer filling system maintained maximum, minimum, and mean levels (means were calculated automatically by the MIRAN SapphIRe 205BXL instrument) of sevoflurane WAG exposure well below the recommended guidelines provided by the Swedish Work Environment Authority and NIOSH. 


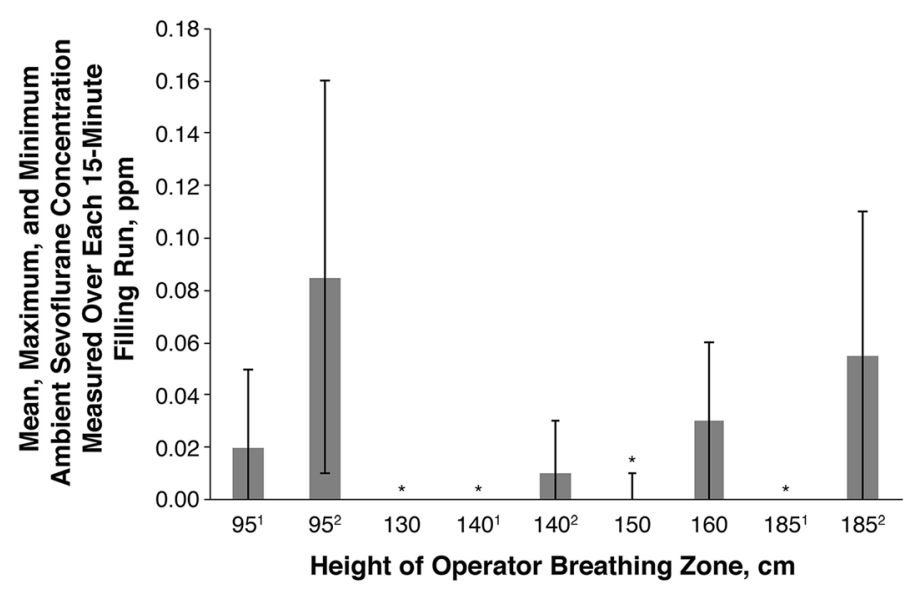

Fig. 2 Ambient sevoflurane concentrations measured at different heights. Columns represent mean sevoflurane concentrations; error bars represent maximum/minimum values. Repeat measurements are from two different operators, indicated by superscript numbers $\left({ }^{1}\right.$ and $\left.{ }^{2}\right)$. Asterisks indicate minimum detection level not reached

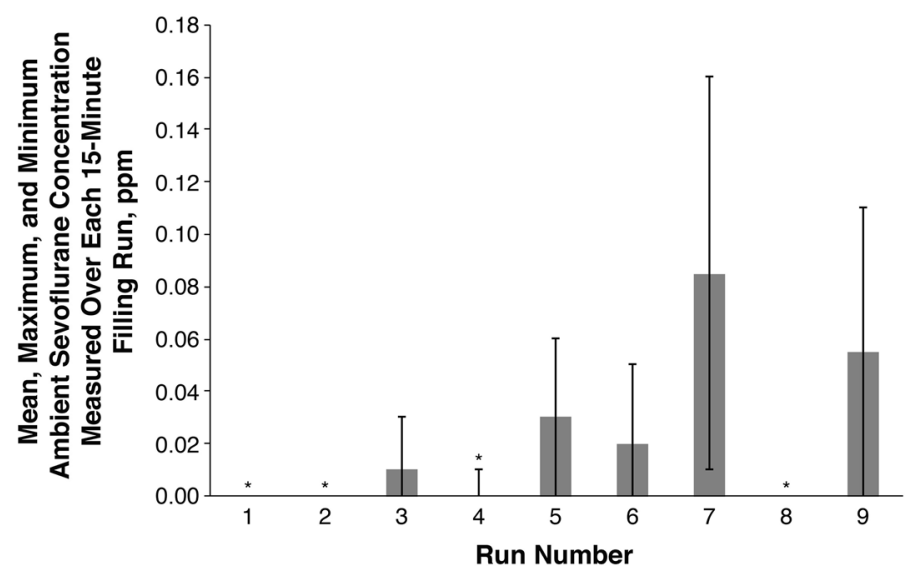

Fig. 3 Sevoflurane exposure by sequential run number during each 15-min filling with closed valving system. Columns represent mean sevoflurane concentrations; error

Across all 45 readings (nine runs, each with five vaporizers filled sequentially) considered together, the mean concentration was $0.10 \mathrm{ppm}$. Among any of the nine runs considered independently, the mean sevoflurane concentration ranged from 0 to $0.09 \mathrm{ppm}$, the maximum sevoflurane concentration ranged from 0 to $0.16 \mathrm{ppm}$, and the minimum sevoflurane concentration ranged from 0 to $0.01 \mathrm{ppm}$. No trends in sevoflurane concentrations were apparent whether the results were considered according to the height of the operator bars represent maximum and minimum values. Asterisks indicate minimum detection level not reached

breathing zone (Fig. 2) or by the order in which the nine runs were conducted over 3 days (Fig. 3).

\section{DISCUSSION}

Leakage of WAG can result from many causes, including but not limited to the filling of anaesthetic vaporizers [11]. The results of this study support the use of the closed anaesthetic filling system, which can be an effective tool as part of an efficient WAG management system. 
The mean value of $0.10 \mathrm{ppm}$ over 45 readings confirms the supposition that the use of the closed vaporizer filling system maintains a level of WAG exposure well below the recommended short-term value of $20 \mathrm{ppm}$ provided by the Swedish Work Environment Authority [15]. The results also fall below the US limit of a TWA of 2 ppm provided by NIOSH and the Occupational Safety and Health Administration [2, 3].

Our study results for the ambient concentration of sevoflurane using filling from an integrated closed valving system were lower than those previously reported by Heijbel et al. [16] and demonstrated consistency regardless of operator height and despite different levels of skill when filling the sevoflurane vaporizer using the closed filling system. In operating rooms, scavenging systems (e.g. passive singlepass or recirculating systems that vent gases to exhaust/disposal sites, passive adsorbers such as canisters of activated charcoal, and active negative-pressure-based systems that remove gases via a central vacuum or dedicated exhaust) are used to help reduce exposure to gases as well as for antiseptic purposes [14]. However, residual sevoflurane concentrations can still exceed the limits recommended by NIOSH [17]. Given that most anaesthesia care providers outside the USA (anaesthesiologists, nurse anaesthetists and assistants) use a closed filling system [5] and considering that the closed vaporizer filling technology results in nearly $60 \%$ less exposure of sevoflurane contamination of ambient air than another filling system [16], our own finding of minimal exposure in breathing zone air validates the usefulness of the closed vaporizer filling technology.

Several limitations of our findings should be noted. This study was not a comparative evaluation but rather a validation of one vaporizer filling system and, therefore, should be evaluated on its own stand-alone merits. An environmental difference in our experiments was the absence of background sevoflurane "scatter", which would be expected in a working operating room environment. Further studies need to be conducted since the data obtained from this study could be affected by the environment, equipment and personnel present in an operating room setting.

\section{CONCLUSIONS}

The use of the closed filling system maintained sevoflurane exposures well below the recommended NIOSH and Swedish guidance in the breathing zone, irrespective of operator height. The use of this closed filling system can help to minimise occupational exposure to halogenated anaesthetic hazards in an operating room environment.

\section{ACKNOWLEDGEMENTS}

Funding. The study, journal's Rapid Service and Open Access Fees were funded by AbbVie Inc., North Chicago, IL, USA. All authors had full access to all of the data in this study and take complete responsibility for the integrity of the data and accuracy of the data analysis.

Medical Writing, Editorial and Other Assistance. General Anesthetic Services Inc. performed the data capture and analysis. Medical writing support was provided by Mayur Kapadia, MD, and Michael J. Theisen, PhD, of Complete Publication Solutions, LLC (North Wales, PA). Support for this assistance was funded by AbbVie, Inc. The authors thank William Narey, Chief Executive Officer of General Anesthetic Services Inc. (South Park, PA), for his contribution to the preparation of the manuscript.

Authorship. All named authors meet the International Committee of Medical Journal Editors (ICMJE) criteria for authorship for this article, take responsibility for the integrity of the work as a whole, and have given their approval for this version to be published.

Disclosures. This work was funded by AbbVie Inc. AbbVie participated in the study design, research, data collection, analysis and interpretation of data, and writing, reviewing, and approving the manuscript. Shane Varughese is an employee of AbbVie and may own AbbVie stock/options. Peter Bacher is an employee of AbbVie and may own AbbVie stock/options. 
Compliance with Ethics Guidelines. This work represents a laboratory study; no ethical committee approval was required and no human subjects were involved.

Data Availability. The datasets generated and analysed during the current study are available from the corresponding author on reasonable request.

Open Access. This article is distributed under the terms of the Creative Commons Attribution-NonCommercial 4.0 International License (http://creativecommons.org/licenses/ by-nc/4.0/), which permits any noncommercial use, distribution, and reproduction in any medium, provided you give appropriate credit to the original author(s) and the source, provide a link to the Creative Commons license, and indicate if changes were made.

\section{REFERENCES}

1. National Institute for Occupational Safety and Health. Publication No. 2007-151: Waste anesthetic gases. Cincinnati: NIOSH; 2007.

2. National Institute for Occupational Safety and Health. Criteria document 77-140: criteria for a recommended standard: occupational exposure to waste anesthetic gases and vapors. Cincinnati: NIOSH; 1977.

3. Occupational Safety and Health Administration. Anesthetic gases: guidelines for workplace exposures. https://www.osha.gov/dts/osta/anestheticga ses/index.html. Accessed 12 Jan 2019.

4. Lucio LMC, Braz MG. do Nascimento Jr P, Braz JRC, Braz LG. [Occupational hazards, DNA damage, and oxidative stress on exposure to waste anesthetic gases]. Rev Bras Anestesiol. 2018;68:33-41.

5. Boiano JM, Steege AL. Precautionary practices for administering anesthetic gases: a survey of physician anesthesiologists, nurse anesthetists and anesthesiologist assistants. J Occup Environ Hyg. 2016;13:782-93.

6. Guirguis SS, Pelmear PL, Roy ML, Wong L. Health effects associated with exposure to anaesthetic gases in Ontario hospital personnel. $\mathrm{Br} \mathrm{J}$ Ind Med. 1990;47:490-7.
7. Saurel-Cubizolles MJ, Estryn-Behar M, Maillard MF, Mugnier N, Masson A, Monod G. Neuropsychological symptoms and occupational exposure to anaesthetics. Br J Ind Med. 1992;49:276-81.

8. Teschke K, Abanto Z, Arbour L, et al. Exposure to anesthetic gases and congenital anomalies in offspring of female registered nurses. Am J Ind Med. 2011;54:118-27.

9. Castellanos M, Xifra G, Fernandez-Real JM, Sanchez JM. Breath gas concentrations mirror exposure to sevoflurane and isopropyl alcohol in hospital environments in non-occupational conditions. J Breath Res. 2016;10:016001.

10. Chotenovsky DJ, Inventor; Baxter Healthcare SA, Baxter International Inc., assignee. Adapter for an anesthetic vaporizer, EP1988957B1, 2007.

11. Yasny JS, White J. Environmental implications of anesthetic gases. Anesth Prog. 2012;59:154-8.

12. Herzog-Niescery J, Botteck NM, Vogelsang H, et al. Occupational chronic sevoflurane exposure in the everyday reality of the anesthesia workplace. Anesth Analg. 2015;121:1519-28.

13. Sárkány $\mathrm{P}$, Tankó B, Simon É, Gál J, Fülesdi B, Molnár C. Does standing or sitting position of the anesthesiologist in the operating theatre influence sevoflurane exposure during craniotomies? BMC Anesthesiol. 2016;16:120.

14. The Office of Research Services, Division of Occupational Health and Safety (DOHS). Waste anesthetic gas. https://www.ors.od.nih.gov/sr/dohs/ Documents/Waste\%20Anesthetic\%20Gas\%20(WAG) \%20Surveillance\%20Program.pdf. Accessed 16 Jan 2019.

15. Arbetsmiljöverket. Hygieniska gränsvärden. https:// www.av.se/arbetsmiljoarbete-och-inspektioner/pub likationer/foreskrifter/hygieniska-gransvarden-afs20181-foreskrifter/. Accessed 16 Jan 2019.

16. Heijbel H, Bjurstom R, Jakobsson JG. Personnel breathing zone sevoflurane concentration adherence to occupational exposure limits in conjunction with filling of vaporisers. Acta Anaesthesiol Scand. 2010;54:1117-20.

17. Braz LG, Braz JRC, Cavalcante GAS, Souza KM, Lucio LMdC, Braz MG. Comparison of waste anesthetic gases in operating rooms with or without an scavenging system in a Brazilian University Hospital. Rev Bras Anestesiol. 2017;67:516-20. 